\title{
Graphene Sensors Operating at Room Temperature for Detection of Low Concentrations of $\mathrm{NO}_{2}$
}

\author{
M. Aleixandre ${ }^{1}$, A.M. Benito ${ }^{2}$, W.K. Maser $^{2}$, M.C. Horrillo ${ }^{1}$ \\ 1 Group of Advanced Sensor Technology (SENSAVAN). Instituto de Tecnologías Físicas y de la Información (ITEFI- \\ CSIC). E-28006 Madrid (Spain). carmen.horrillo.guemes@csic.es \\ 2 Group of Carbon Nanostructures and Nanotechnology (G-CNN). Instituto de Carboquímica (ICB-CSIC). \\ E-50018 Zaragoza (Spain)
}

\begin{abstract}
1. Abstract
Reduced graphene oxide decorated with palladium was used to fabricate sensors that operated at room temperature. The sensors were exposed to different mixtures of dry or synthetic air and $\mathrm{NO}_{2}$ in the range of 0.1 ppmv to 1 ppmv. The sensors showed a good performance at room temperature, opening the possibility of using this kind of sensors for very low power $\mathrm{NO}_{2}$ sensing.
\end{abstract}

\section{Introduction}

Small sensors for the detection of toxic gases such as $\mathrm{NO}_{2}$ are attracting a lot of interest in recent years for their use in environmental pollution monitoring. Sensors based on conductivity changes are some of the most used types of gas sensors, but they usually require heating to work. While the power need by this heating tends to be in the order of $\mathrm{mW}$, there is a demand for even lower power consumption to get an overall smaller and more autonomous system (without battery). Modified reduced graphene (rGO) has shown good performance as an $\mathrm{NO}_{2}$ sensor [1], and in this work its performance as low temperature sensor for low $\mathrm{NO}_{2}$ concentrations is being studied further.

\section{Experimental setup}

Graphite oxide was first prepared using a modified Hummer's method from graphite powder by oxidation with $\mathrm{NaNO}_{3}, \mathrm{H}_{2} \mathrm{SO}_{4}$ and $\mathrm{KMnO}_{4}$ in an ice bath as reported elsewhere [2]. Next, thermal exfoliation/reduction of the resulting graphite oxide was carried out at $700{ }^{\circ} \mathrm{C}$ for $15 \mathrm{~min}$ in Argon atmosphere getting the reduced graphene oxide material (rGO). Finally, the deposition of the palladium nanoparticles on rGO was performed by microwave-assisted decomposition of a palladium complex, $\left[\mathrm{Pd}_{2}(\mathrm{dba}) 3 \cdot \mathrm{CHCl}_{3}\right]$ (being $\mathrm{dba}=$ trans, transdibenzylideneacetone) in the presence of $\mathrm{rGO}$ suspended in toluene at $110^{\circ} \mathrm{C}$ for $3 \mathrm{~min}$, following the procedure reported elsewhere [3].

The obtained rGO-Pd material, containing $11.4 \%$ of $\mathrm{Pd}$
(Fig. 1), was suspended in NMP at a concentration of $0.5 \mathrm{mg} / \mathrm{mL}$ in an ultrasonic bath for two hours.

The graphene solution was drop casted into micromachined silicon substrates with integrated heaters. Two sensors (R1 and R2) were exposed to a flow rate of $200 \mathrm{ml} / \mathrm{min}$ of synthetic air for 60 minutes to obtain a steady base line. Then they were exposed to a mixture of synthetic air and $\mathrm{NO}_{2}$ at the same flow rate. The gas concentrations were generated by dynamic dilution with mass flow controllers from bottles of 2 ppmv of $\mathrm{NO}_{2}$ in synthetic air. The sensors were tested at room temperature, $50{ }^{\circ} \mathrm{C}$, and $100^{\circ} \mathrm{C}$.

\section{Discussion}

The sensors behave as p-type semiconductors, lowering the resistance during the exposure to the $\mathrm{NO}_{2}$ oxidizing gas. The responses of the sensors, calculated as resistance baseline/final resistance, can be seen in Fig. 2. Using these response plots the sensitivity was calculated as the slope of a minimum square linear fit of the curve. Then that sensitivity was used to calculate the minimum detectable concentration, as shown in Fig. 3. The sensor worked better at room temperature and the minimum detectable concentration was as low as 10-20 $\mathrm{ppb}$. This type of sensor is very promising for its use at room temperature in environmental applications. In addition the sensor has a resistance under $1 \mathrm{M} \Omega$ making it usable for simple interrogation electronic circuits.

\section{References}

[1] R. Furue, E. P. Koveke, S. Sugimoto, Y. Shudo, S. Hayami, S. Ohira, K. Toda, Arsine gas sensor based on goldmodified reduced graphene oxide, Sensors and Actuators B: Chemical, Volume 240, 2017, pp. 657-663,

[2] C. Vallés, J.D. Núñez, A.M. Benito, W.K. Maser, Flexible conductive graphene paper obtained by direct and gentle annealing of graphene paper, Carbon 50, 2011, pp. 835-844. [3] M. Cano, A.M. Benito, W.K. Maser, E.P. Urriolabeitia. High catalytic performance of palladium nanoparticles supported on multiwalled carbon nanotubes in alkene hydrogenation reactions. New J. Chem., 2013, 37, pp. 19681972. 

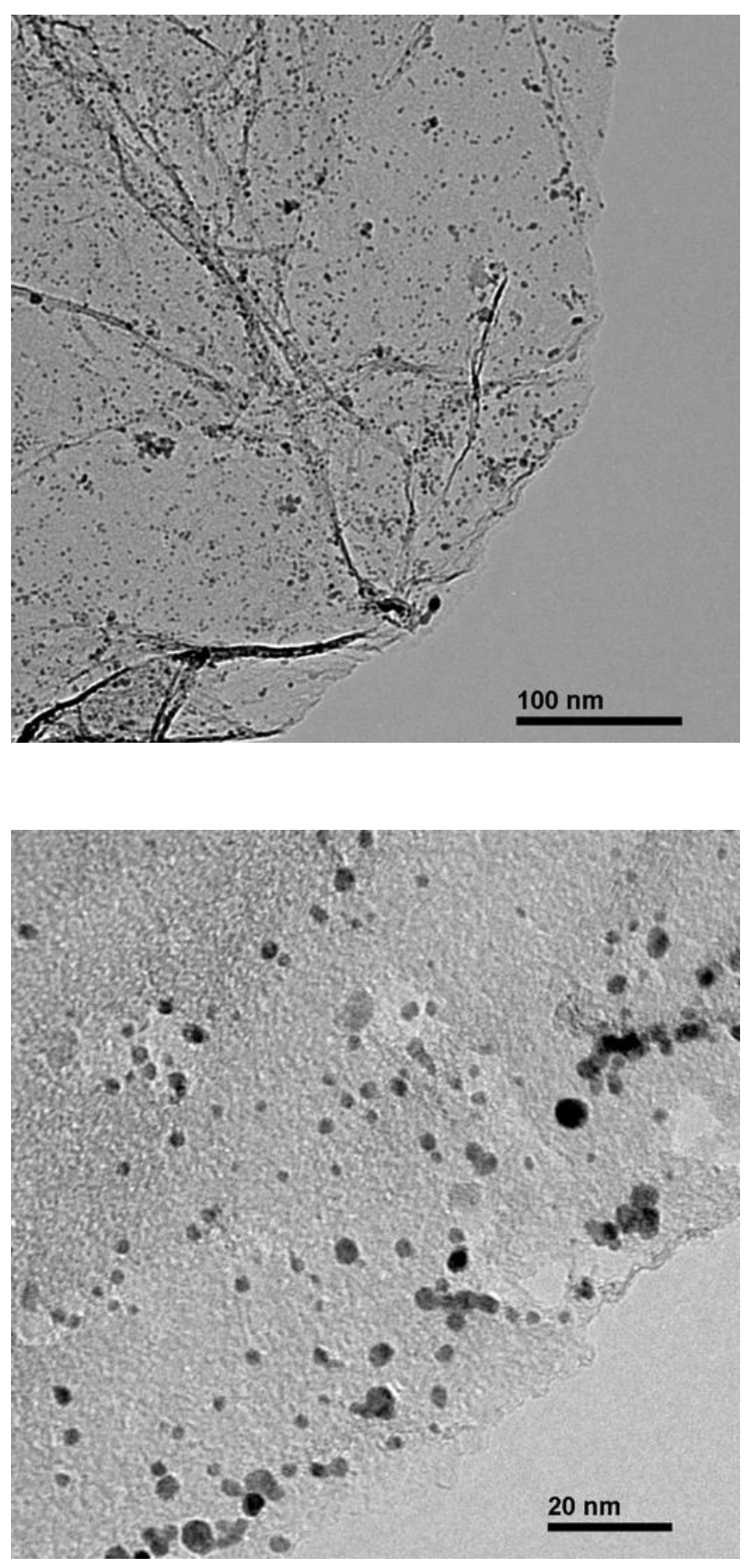

Fig. 1. TEM image of $\mathrm{rGO}-\mathrm{Pd}$ showing homogeneous and very narrow size distribution of palladium nanoparticle sizes around 2 to $4 \mathrm{~nm}$.
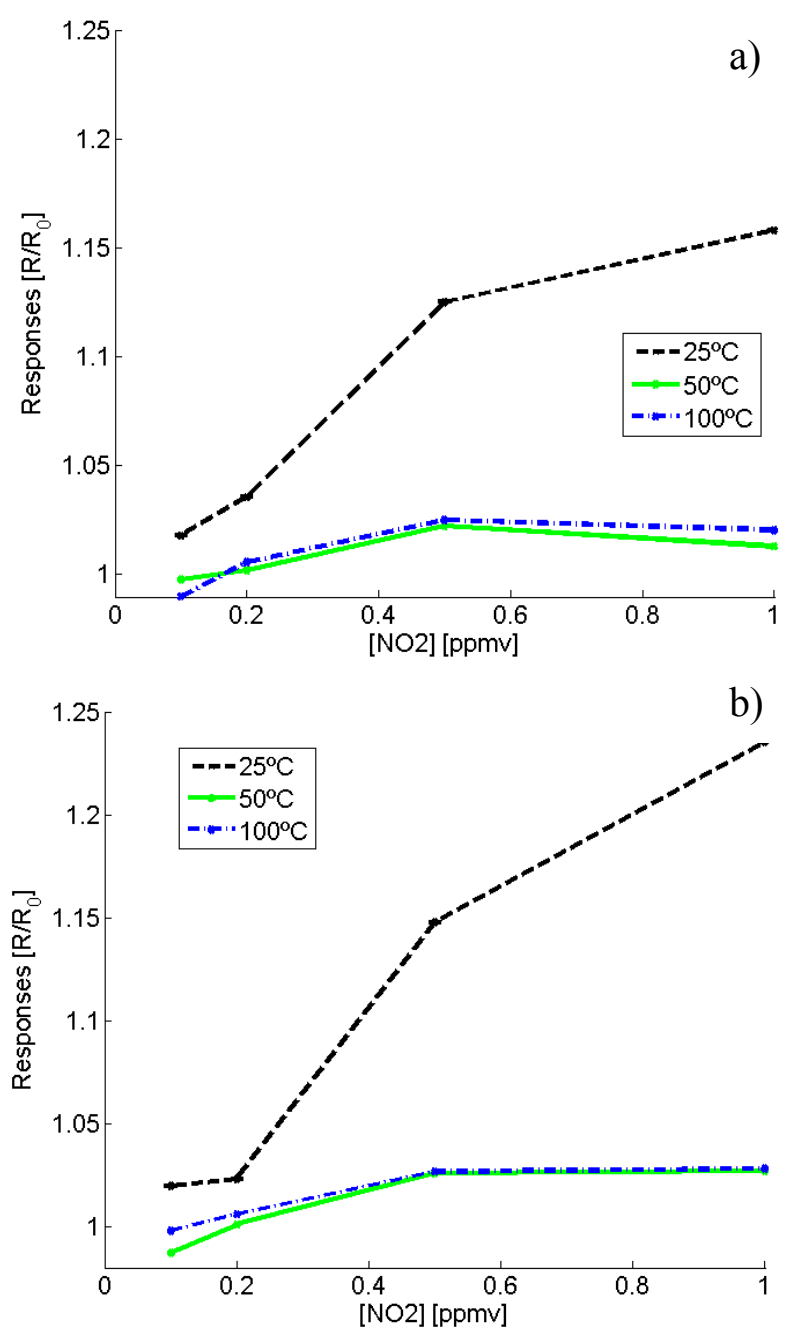

Fig. 2. Response of the sensors at different temperatures to different concentrations of $\mathrm{NO}_{2}, \mathrm{R} 1$ in a) and $\mathrm{R} 2$ in b).

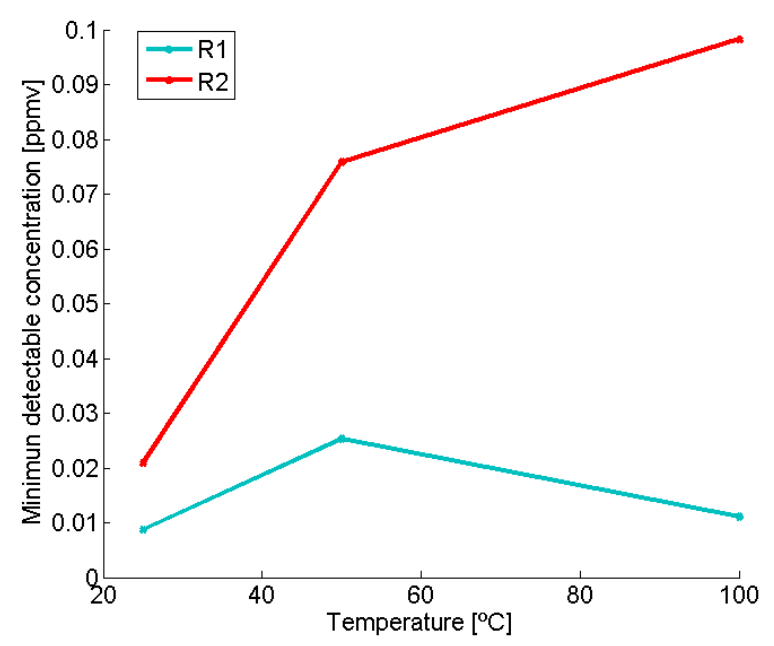

Fig. 3. Minimum detectable concentration at different operating temperatures. 